\title{
Masamu Program, a US-Africa Partnership
}

\section{Overtoun Jenda and Edward Lungu}

\section{Introduction to Masamu}

The primary goal of the Masamu (note that "masamu" means mathematics in Southern Africa) Program is to enhance research in the mathematical sciences and related areas within the Southern Africa Mathematical Sciences Association (SAMSA) institutions and beyond through promotion of international research collaboration. The Masamu Program was established in 2010 with the assistance of the National Science Foundation through an Auburn University-SAMSA Memorandum of Understanding (MOU) with particular emphasis on increasing and sustaining research collaborations between mathematicians in the US and the Southern Africa region (Angola, Botswana, Eswatini, Lesotho, Malawi, Mozambique, Namibia, South Africa, Tanzania, Zambia, and Zimbabwe). The strong collaborative support from African and US universities has made the Masamu Program viable and able to expand its reach.

A key component of the Masamu Program is the Masamu Advanced Study Institute (MASI) and Workshop Series in mathematical sciences and related areas, which provides a platform for such collaboration. This is done through the US-Africa Collaborative Research Network (CRN), consisting of US and African senior researchers in several areas of the mathematical sciences and related areas together with additional collaborators from Canada and Europe. The primary goal of the CRN is to improve the

Overtoun Jenda is co-chair of the Masamu Steering Committee and professor of mathematics and assistant provost for Special Projects and Initiatives at Auburn University. His email address is jendaov@auburn.edu.

Edward Lungu is co-chair of the Masamu Steering Committee and professor of mathematics and dean of the Faculty of Science at Botswana International University of Science and Technology. His email address is 1ungue@ biust.ac. bw.

For permission to reprint this article, please contact: reprint-permission aams.org.

DOI: https://dx.doi.org/10.1090/noti2213 human infrastructure in the mathematical sciences in both the US and Sub-Saharan Africa, especially among women and underrepresented minorities. The target audiences of MASI are graduate and undergraduate students, postdocs, and early-career faculty (those whose rank is less than associate professor), while the workshops are also open to more senior faculty and other researchers in the mathematical sciences and related areas. The Masamu Program especially encourages applications from undergraduate students who have participated in Research Experiences for Undergraduates (REU) programs.

The first institute and workshops were held in 2011 in Livingstone, Zambia. The primary focus of the inaugural institute was on epidemiological modeling. Additional connections were then developed in other areas where there were mutual research strengths, resulting in an expanded CRN that now consists of 82 research mathematicians from Sub-Saharan Africa, US, Canada, China, and Europe from 46 collaborating colleges and universities and research laboratories/centers/institutes. Each research group is co-led by US and African senior research faculty and is subdivided into research teams consisting of senior mathematicians, early-career faculty, students, and postdoctoral researchers.

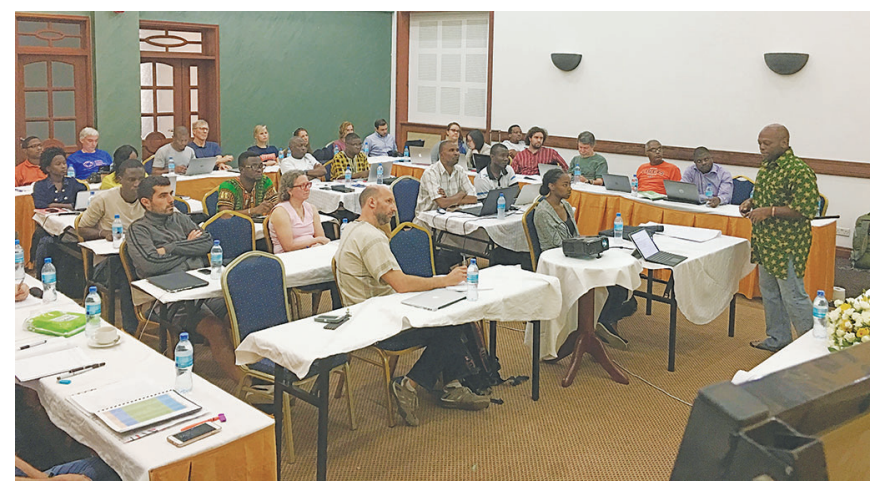

Figure 1. MichaelWashington of CDC presenting to the Mathematical Biology Research Group in Arusha,Tanzania, in 2017. 
Each research team includes both US and African participants. African and American researchers work side by side but with different techniques and different questions. This diversity of perspective provides an opportunity for CRN to broaden the spectrum of questions to be studied and the methods/approaches for exploring these questions, resulting in increased research activity and productivity for both African and US participants.

\section{Programming}

SAMSA holds a 4-day international research conference during Thanksgiving week each year, and the Masamu Program runs a 10-day MASI and Research Workshop that overlaps with the conference. US-Africa CRN members take advantage of this gathering and participate in the conference, work on problems, plan research activities for the subsequent year, and present their results at the conference. The conference enhances the institute by providing Masamu participants a platform to make presentations and meet potential research collaborators, and in turn the institute enhances the conference by the lectures presented by CRN senior researchers. Indeed, the conference helps MASI participants learn about new research problems and techniques, since not all SAMSA participants are able to

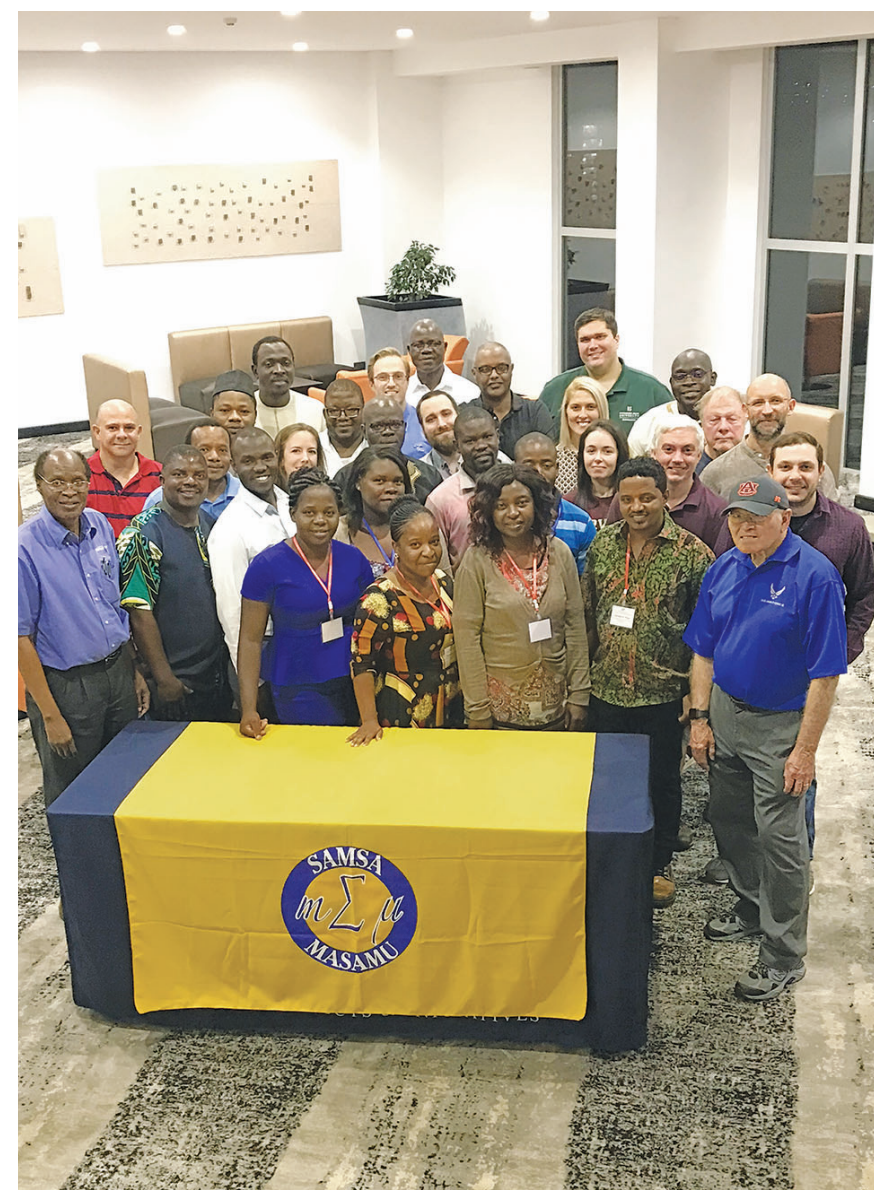

Figure 2. 2019 MASI participants in Malawi. attend the institute. For example, a Tanzanian mathematician gave a talk at SAMSA 2012 on "connected dominating sets of vertices in graphs" which had some distant connections to US work in this area. The mathematician was then invited to MASI 2013, and this area is now a thriving research area for US students and faculty together with their African counterparts. These activities enable the network to produce an increased number of new PhDs in both the US and Sub-Saharan Africa, more joint research publications, and long-term US-Africa partnerships consisting of researchers from diverse backgrounds. Indeed, the focus is on building long-term US-Africa collaborations rather than a one-off participation, and thus long-term involvement is expected of all participants.

The Kovalevskaia Research Grants program was established in 2014 as an initiative of the Kovalevskaia Fund, within the SAMSA Masamu Program. These grants are awarded every two years to two upcoming female mathematicians (one in pure and another in applied mathematics) from the Sub-Saharan Africa region who have demonstrated outstanding research and publications in pure or applied mathematics.

One of the 2016 Kovalevskaia Research Grants recipients was Dr. Winifred Nduku Mutuku, a senior lecturer

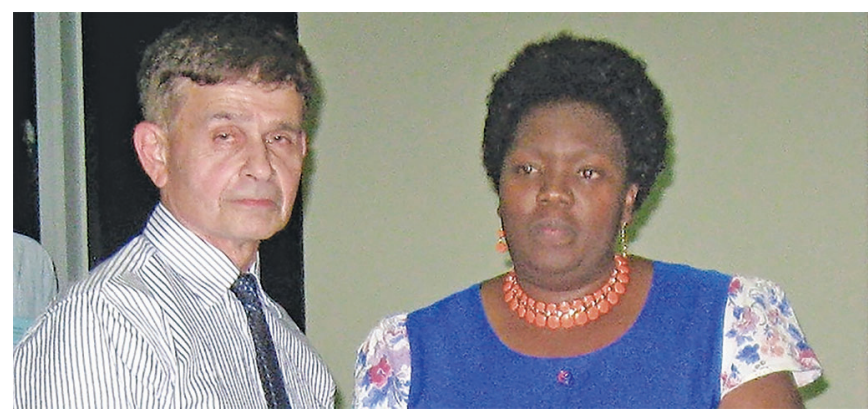

Figure 3. Dr. Neal Koblitz and Dr. Winifred Nduku Mutuku at the Kovalevskaia Research Awards ceremony in Pretoria in 2016.

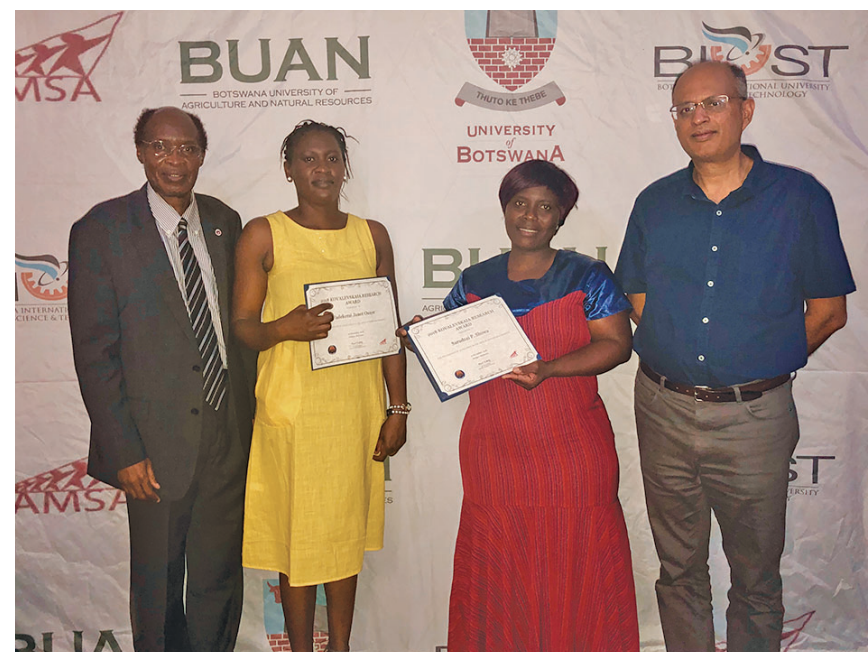

Figure 4. Kovalevskaia Research Awards in Palapye, Botswana, in 2018. 
in the Department of Mathematics and Actuarial Science at Kenyatta University, Kenya. Dr. Mutuku received her BS in Education and MS in Applied Mathematics at Kenyatta University and her PhD in Applied Mathematics at Cape Peninsula University of Technology, South Africa, specializing in mathematical modeling and computation of fluid mechanics. She is active in research and currently serves as Chair of the Departmental Board of Postgraduate Studies and Departmental Research Coordinator.

The Masamu Program also sponsors a Research Workshop each year as part of the Masamu Advanced Study Institute (MASI) and the following workshops as part of the SAMSA conference: the Career Development Workshop, the High Performance Computing Workshop, the STEM Education Workshop, and the Department Heads, Chairs and Senior Research Scientists Workshop. The Masamu Program also sponsors colloquia, faculty exchanges, lecture series, and study abroad programs. One of the most sought-after workshops is the STEM Education Workshop in which Masamu runs partnerships with local authorities in host countries during the SAMSA conference. The workshop examines and discusses current evidence-based models, best practices, and strategies for increasing the quantity and quality of undergraduate and graduate degrees in the mathematical sciences. Of particular interest is the opportunity the annual workshop provides to US research faculty and postdocs to collaborate with local teachers in the design of new educational enrichment activities for motivating and exciting high school students to major in mathematics. This has motivated US participants to be more involved in K-12 STEM education back home.

Finally, in 2021 SAMSA will celebrate its 40-year anniversary together with the postponed (due to COVID-19) 10-year anniversary of MASI. To commemorate these special occasions, the US-Africa CRN will host a 2-day international research symposium in lieu of the standard research workshop held at the end of MASI. The theme of the symposium is "Mathematics Connecting to One Health" focusing on the interconnection of human, animal, and environmental health, which are all research focus areas of the US-Africa CRN. At the symposium, we will highlight the work done by the network and work on future collaborative research areas and knowledge transfer to inform policy and practices.

\section{Accomplishments}

The Masamu Program has had nine memorable face-toface annual Institutes and Workshop Series held in seven different Southern African countries from 2011 to 2019 with 340 participants (including repeats) from 19 countries, with 141 (139 from the US) from North America. The 10th MASI, which took place in 2020, was held virtually due to the pandemic. Eight additional workshops and lectures have been held outside the annual MASI and Workshop Series over the years.

MASI is a true retreat where you can focus $100 \%$ on your research, far away from home and with zero distractions. This has proven to be extremely helpful for US graduate students and faculty, especially those that spend a lot of time teaching. Indeed, most claim that they do more research at the institute in those 10 days than they do during the rest of the academic year. This is a testament to the intense focus on research and being surrounded by top students and faculty from around the world bringing together their research methods and ideas. Productivity is also enhanced by the flexibility that allows participants to work and collaborate on multiple projects and continuously learn new techniques, which is very hard for them to match when they are back in the US. Those that have participated in other institutes in the US say that their experience at MASI is comparable to their visits to other research institutes. What has made MASI successful is the absence of the mentality of the colonial era that espoused the belief that European mathematicians were better than their African counterparts and that Western mathematicians had nothing to learn from their African colleagues. CRN participants are all on equal footage, and this has helped build solid, lifelong collaborations that have strengthened research activity in all participating African and US research programs.

Solutions to the research questions being studied by CRN research teams have important applications in pure and applied mathematics, industry, government, and in society in general. In particular, solutions to these questions have applications in national security, network coverage, surveillance, transportation, finance, and statistics. They also advance understanding of the spread of disease and biodiversity, which have important policy implications as demonstrated by the COVID-19 crisis. The study of tumor

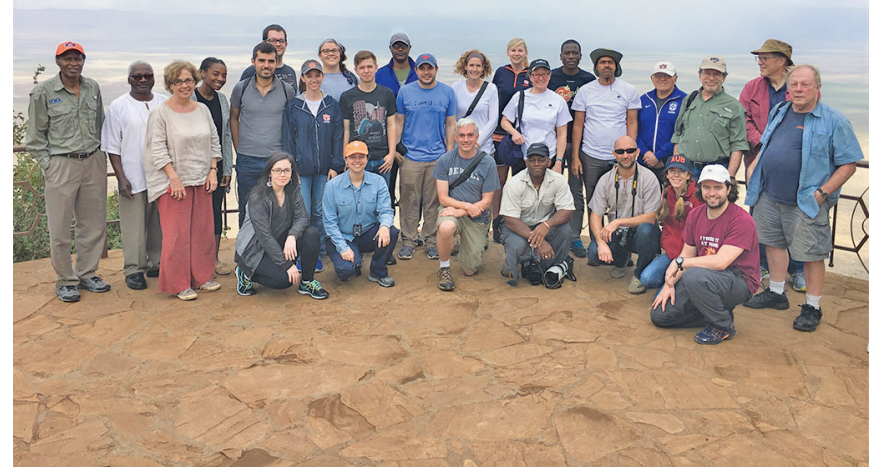

Figure 5. Participants visiting Ngorongoro Crater inTanzania in 2017. 
growth, cell motility, and DNA structure have significant medical applications, and mathematical models involving climate data provide important predictions of the impacts of climate change on future human and animal behavior and their interactions.

CRN has grown by 100\% since 2011 (from 41 to 82), and we expect the number of participants to continue to grow as we increase the size of each research group and add more research areas. Senior research faculty that are interested in attending the SAMSA conference or would like to be a member of the CRN should contact Paul Horn at the University of Denver and Peter Johnson at Auburn University (for discrete mathematics), or Suzanne Lenhart at the University of Tennessee Knoxville (for mathematical biology), or email masamu@auburn. edu for all other areas. Members of the network lead or participate in research teams and should be prepared to attend MASI whenever their schedule allows.

Early-career faculty, graduate and undergraduate students, and postdoctoral researchers can apply to the Masamu Advanced Study Institute (MASI) at www . masamu . auburn.edu. Participants are selected by the Masamu Program Steering Committee. Selection criteria includes (1) research potential or experience as verified by support letters, and (2) diversity considerations (disability, gender, underrepresented minority, type of college or university). The number of MASI participants is capped at 34 (17 from US) with 10 slots reserved for senior researchers. Thus the selection for MASI is competitive.

\section{Financial Support}

The MASI sustainability model necessitates that faculty and postdocs seek their own funds for attending the institute. The Masamu Program uses NSF funding to support local expenses at the institute and the SAMSA conference depending on financial need. However, faculty and

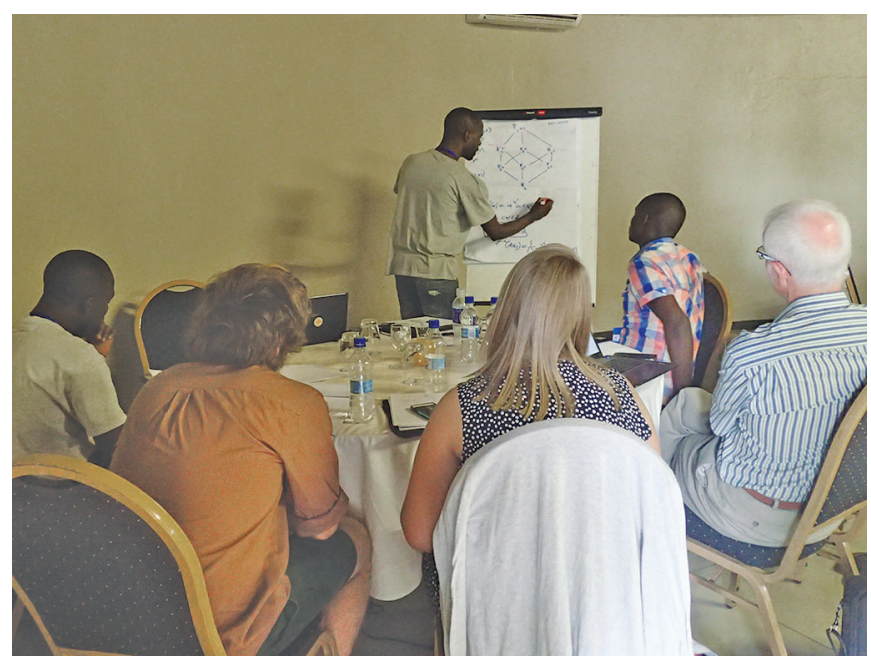

Figure 6. GraphTheory Research Group in Victoria Falls, Zimbabwe, in 2014. postdocs are urged to find funds to cover their airfare. Selected students will be fully supported. Note that NSF support is only available to US citizens and permanent residents. Sub-Saharan participants, including faculty and students, may also apply for funds from the Simons Foundation "Research and Graduate Studies in Mathematics and its Applications (RGSMA): A Network Approach" project.

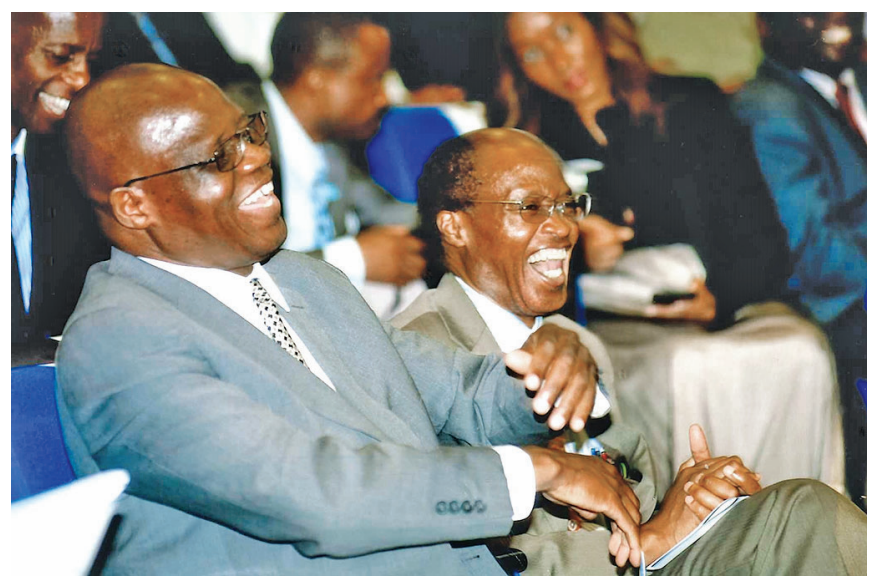

Figure 7. Edward Lungu and Overtoun Jenda at the 2018 SAMSA conference opening ceremony in Palapye, Botswana.

\section{Masamu Program Management}

The Masamu Program is managed by the Masamu Steering Committee consisting of five representatives from SubSaharan Africa, five from the US, and one from Europe. The Auburn University Office of Special Projects and Initiatives administers the US-Africa Collaborative Research Network and runs MASI and workshops on site in Africa. For general inquiries about the program, please contact Dr. Brittany McCullough, Program Analyst, at masamu@auburn . edu.

ACKNOWLEDGMENTS. This article is based on work supported by NSF Grant Nos. DMS-1050259, DMS1343651, and DMS-2015425, the Simons Foundation Africa Mathematics Project Grant, and the Kovalevskaia Fund.

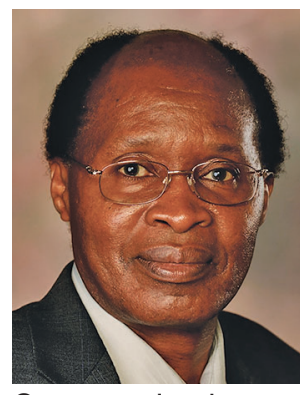

Overtoun Jenda

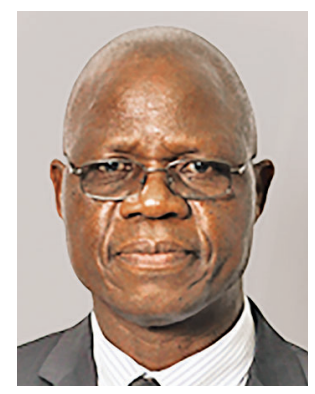

Edward Lungu

\section{Credits}

Figures 1-6 are courtesy of Brittany McCullough.

Figure 7 is courtesy of Edward Lungu.

Photo of Overtoun Jenda is courtesy of Auburn University. Photo of Edward Lungu is courtesy of Edward Lungu. 